\title{
Parametric study on free vibration and instability of a functionally graded cracked shaft in a rotor-disc-bearing system: finite element approach
}

\author{
Debabrata Gayen ${ }^{1, *}$, Debabrata Chakraborty ${ }^{1}$, and Rajiv Tiwari ${ }^{1}$ \\ ${ }^{1}$ Department of Mechanical Engineering, Indian Institute of Technology Guwahati, Guwahati 781039, Assam, India
}

\begin{abstract}
Free vibration and stability analysis are studied for a rotor-disk-bearing system having a radially functionally graded (FG) shaft with a transversely fully open crack, based on finite element (FE) approach. Both viscous and hysteretic internal damping are incorporated in the FE model of FG cracked shaft using two nodded Timoshenko beam element having four degrees of freedom (DOFs) at each node. Material properties of the FG cracked shaft are assumed temperature dependent and graded along radial direction following different material gradation law. FG shaft is made of two constituents material namely zirconia $\left(\mathrm{ZrO}_{2}\right)$ and stainless steel (SS) where metallic (SS) contain is decreasing towards the outer diameter of the shaft. Extended Hamilton's principle is employed to derive the system equations of motion (EOMs) of the FG cracked shaft system. A complete code is developed in MATLAB for correcting the formulation of modeling of crack and verified with existing published results. Influences of different material gradient index, temperature gradients, size and location of crack, viscous and hysteretic internal damping, slenderness ratio, and boundary condition on dynamic responses of the FG cracked shaft system are studied.
\end{abstract}

Keywords. FG cracked shaft; Stability threshold speed; Material gradient index; Temperature dependent material property

\section{Introduction}

Functionally graded materials (FGMs) have been constituted as high performance, thermal resistance, multi-functional, microscopically inhomogeneous materials whose thermo-mechanical properties graded smoothly and continuously in a pre-determined directions using different law of material gradations to achieve superior material properties under thermal environment. Historically, in 1984, concept and application of FGMs were first visualized in Japan during space project, reported by Koizumi [1]. Later, applications of FGMs have been expanded in aero-space, automotive, electronics and biomedical applications etc. In last four decades, many studies related to FGMs structures were reported and some of the valuable works are summarized here. Miyamoto et al. [2] reported fundamentals, manufacturing processes, design and current application of FGMs. Reddy and Chin [3] presented thermo-mechanical responses for FG structure (plates, cylinders, etc.) using FE formulation. Mahi et al. [4] reported temperature dependent free vibration response of a FG beam based on higher order shear deformation theory. Shahba et al. [5] presented free vibration and stability analysis for an axially tapered FG beams (Timoshenko) through a FE approach. Gayen and Roy [6] studied vibration and stability analysis of a FG spinning shaft system based on Timoshenko beam theory (TBT).

Shafts are basic components in high-performance rotating machinery equipment, used in the requirement of higher power, high operational speed. Therefore, prediction of dynamic responses of a shaft system is importance and many studies reported in this direction for the homogeneous shaft and very few for FGMs. Some of them are summarized here. Papadopoulos [7] reported review works of cracked rotor for dynamic analysis. Nelson and Mcvaugh [8] studied dynamic responses of a shaft with gyroscopic effect, rotary inertia effect, and shear deformation effect. Zorzi and Nelson [9] extended the work [8] and included both viscous and hysteretic internal damping effect in the same FE model. Based on FE approach, Ku [10] studied whirl speeds and damped stability for a rotor-bearing system, considering both internal viscous and hysteretic damping.

Even though small crack leads a dangerous and catastrophic failure of structural components in the studies of rotor dynamical systems. Therefore, some of the important works are summarized here. Papadopoulos and Dimarogonas [11] studied coupled vibration and stability regions for cracked rotor. Huang et al. [12] studied dynamic response and stability analysis of a rotating cracked shaft. Chen and Chen [13] studied stability analysis of a rotating cracked shaft subjected to

Corresponding author: d.gayen@iitg.ernet.in 
the end load based on TBT. Sekhar and Dey [14] studied stability threshold speed of a rotor system having single and two transverse cracks and reported a parametric studies on the instability speed. Also, few studies relating to the dynamic analysis of FG shaft systems are reported here. Gayen et al. [15] reported dynamic responses of a rotor-bearing system with a fully open transverse cracked FG shaft using FEM. Gayen et al. [16] reported a FE based dynamic responses of a rotorbearing system with a breathing cracked FG shaft.

Even though a large number of works reported in the direction of analysis of FGM structure, free vibration and stability analysis of homogeneous cracked shaft for a long time. However, hardly any works available in the area of temperature dependent free vibration and stability analysis of cracked FG shaft system. Therefore, aim of the present 'study is to develop a FE model for analysis of cracked FG shaft system with temperature dependent material properties and to study the effect of important parameters such as gradient index, temperature gradient, size and location of crack, internal viscous and hysteretic damping, slenderness ratio and boundary condition on the dynamic responses.

\section{Thermo-mechanical properties of an FG Shaft}

Since FGMs structures mostly used in high temperature environment, constituents of FGMs may reflect the temperature dependent properties. Therefore, Touloukian [17] reported the temperature dependent material properties $P$ along radial direction of FG shaft as,

$$
P(T)=P_{0}\left(P_{-1} T^{-1}+1+P_{1} T+P_{2} T^{2}+P_{3} T^{3}\right)
$$

where $P_{0}, P_{-1}, P_{1}, P_{2}$ and $P_{3}$ are the coefficient of temperature $T$ (in $\mathrm{K}$ ) and are unique for every constituent materials.

Material properties $P$ (Young's modulus $E$ (in $\mathrm{Pa}$ ), Poisson's ratio $v$, thermal conductivity $K$ (in $\mathrm{W} / \mathrm{m} \mathrm{K}$ ), and mass density $\rho$ (in $\left.\mathrm{Kg} / \mathrm{m}^{3}\right)$ ) in the $\mathrm{FG}$ shaft are graded along the radial direction $(y)$ as a function of temperature $(T)$ (Reddy and Chin [3])

$$
\begin{aligned}
& P(y, T)=P_{m}(T)+\left\{P_{c}(T)-P_{m}(T)\right\}\{V F\}^{k}, \\
& V F=\left(y-R_{m}\right) /\left(R_{c}-R_{m}\right), R_{c} \leq y \leq R_{m}, 0 \leq k \leq \infty
\end{aligned}
$$

where $R$ is the radius of the shaft, subscripts $m$ and $c$ refer to metal and ceramic respectively and power law index $k=0$ and $k=\infty$ denotes the two extremes of completely homogenous ceramic and metal respectively. In Eq. (2), $k=1$ represent the linear law of material gradation and for other values of $k$ represent the power law of material gradation (P-FGM).

Material properties distribution according to exponential law of material gradation (E-FGM)

$$
\begin{aligned}
& P(y, T)=P_{m}(T) e^{\lambda\left(y-R_{m}\right)}, \\
& \lambda=\ln \left\{P_{c}(T) / P_{m}(T)\right\} /\left(R_{c}-R_{m}\right), R_{m} \leq y \leq R_{c}
\end{aligned}
$$

Material properties distribution according to sigmoid law of material gradation (S-FGM)

$$
\left.\begin{array}{l}
P(y, T)=P_{m}(T)+\left\{P_{c}(T)-P_{m}(T)\right\}\{V F\}^{n}, \\
R_{m} \leq y \leq\left(R_{m}+R_{c}\right) / 2 \\
P(y, \mathrm{~T})=P_{c}(T)+\left\{P_{m}(T)-P_{c}(T)\right\}(1-\{V F\})^{n}, \\
\left(R_{m}+R_{c}\right) / 2 \leq y \leq R_{c}
\end{array}\right\}
$$

where $n$ is sigmoid law of material gradient index.

Temperature distributions along radial direction in FG shaft are computed using steady-state one dimensional Fourier equation of heat conduction law and applying the thermal boundary conditions (i.e. at $y=R_{m}, T=T_{m}$ and at $\left.y=R_{c}, T=T_{c}\right)$ as

$$
\frac{d}{d y}\left[K(y) \frac{d T}{d y}\right]=0
$$

Temperature distribution according to power law of material gradation (P-FGM) as

$$
T(y)=T_{m}+\left(T_{c}-T_{m}\right) \frac{\left[\sum_{j=0}^{5}\left\{\frac{(-1)^{j}}{j k+1}\left(\frac{K_{c m}}{K_{m}}\right)^{j}(V F)^{j k+1}\right\}\right]}{\left[\sum_{j=0}^{5} \frac{(-1)^{j}}{j k+1}\left(\frac{K_{c m}}{K_{m}}\right)^{j}\right]}
$$

Temperature distribution according to exponential law of material gradation (E-FGM) as

$$
T(y)=\mathrm{A}+\mathrm{B} e^{-\lambda\left(y-R_{m}\right)}, R_{m} \leq y \leq R_{c}
$$

where $K_{c m}=K_{c}-K_{m}, \mathrm{~A}=T_{m}-\left(T_{c}-T_{m}\right) / e^{-\lambda\left(R_{c}-R_{m}\right)}-1$, $\mathrm{B}=\left(T_{c}-T_{m}\right) / e^{-\lambda\left(R_{c}-R_{m}\right)}-1, \lambda=\ln \left(K_{c} / K_{m}\right) /\left(R_{c}-R_{m}\right)$.

These graded thermo-mechanical material properties are used in FE modeling of FG shaft.

\section{FE formulation of an FG cracked shaft system}

The rotor-disk-bearing system is considered to comprise a set of interconnecting components consisting of transverse cracked shaft elements with distributed mass and elasticity, rigid disks and linear bearings shown in Fig. 1.

\subsection{Finite shaft element with a fully open transverse crack}

The FG cracked shaft with identical un-damped isotropic bearings are discretized and shown in Fig. 1(a), where total length is $L$, element length is $L_{e}$ and diameter is $D$ and $\alpha$ is the depth of crack located at distance $L_{c}$ from left end support of shaft. The crack orientation 


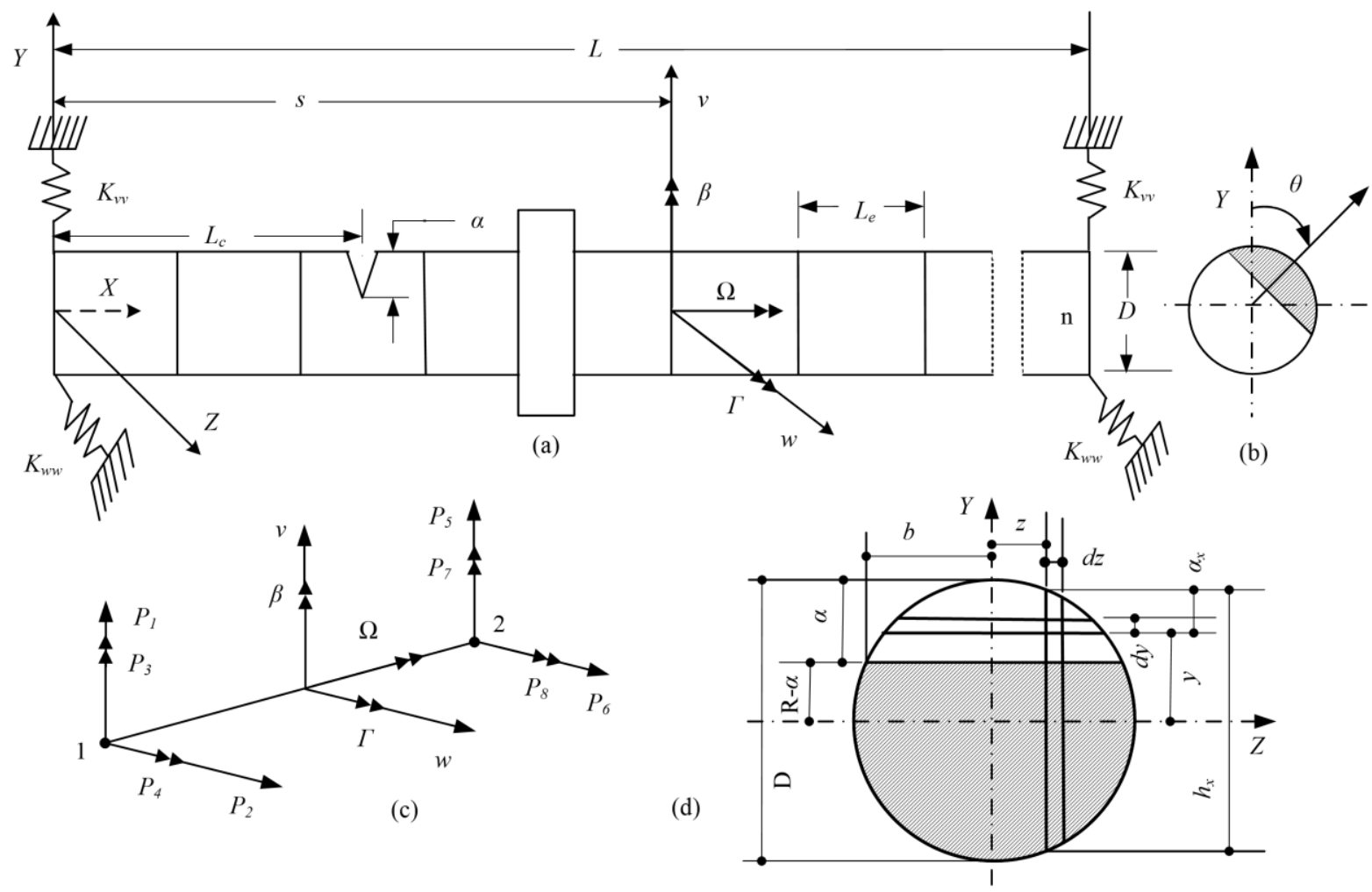

Fig. 1 Rotor-disk-bearing system with a cracked FG shaft: (a) Coordinate system and FE discretization (b) Crack orientation (c) General loading (d) Geometry of cracked section

denoted by $\theta$, shown in Fig. 1(b). Fig. 1(c) shows the shaft element subjected to shear forces $P_{1}, P_{2}, P_{5}$ and $P_{6}$ and bending moments $P_{3}, P_{4}, P_{7}$ and $P_{8}$, rotating at speed $\Omega, v$ and $w$ are the translation displacements along $Y$ and $Z$ direction, and $\beta$ and $\Gamma$ are the rotational displacements about $Y$ and $Z$ at a distance $s$ from the left end of a cross-section of the shaft. Fig. 1(d) shows the cross-section of the cracked shaft having fully open transverse crack (crack orientation, $\theta=180^{\circ}$ ) with crack half-width $b$.

The LFCs of cracked FG shaft are computed using Paris's equations [18] and Castigliano's theorem in conjunction with the SIFs expression and the additional displacement $u_{i}^{c}$ due to crack is expressed as

$$
\begin{aligned}
& u_{i}^{c}=\frac{\partial}{\partial P_{i}} \int_{0}^{\alpha_{x}} \frac{\left[\left(\sum_{i=1}^{4} K_{I i}\right)^{2}+\left(\sum_{i=1}^{4} K_{I I i}\right)^{2}+m\left(\sum_{i=1}^{4} K_{I I I i}\right)^{2}\right]}{E(y, T)} d y, \\
& m=\{1+v(y, T)\}
\end{aligned}
$$

where SIFs $K_{\mathrm{I}}, K_{\mathrm{II}}$ and $K_{\mathrm{III}}$ corresponding to modes I, II, and III expressions in Eq. (8) are taken from Tada et al. [18] and $i=1,2,3,4$ are load indices.

Finally, LFCs for an FG shaft with $\theta=180^{\circ}$ are computed as follow (refer Fig. 1(d))

$$
C_{i j}^{c}=\frac{\partial}{\partial P_{i}} \int_{-b}^{b} \frac{\partial u_{i}^{c}}{\partial P_{j}} d z
$$

where $\alpha_{x}=(\alpha-R)+\sqrt{R^{2}-z^{2}}$ and $b=\sqrt{R^{2}-(R-\alpha)^{2}}$.

Here, integrations are carried out to obtain LFCs of the FG cracked shaft considering $E(y, T)$ and $v(y, T)$ as a function of $y$ as well as $T$, unlike homogeneous shaft where material properties are considered as constant and could be taken out of integration in Eq. (9). Using Eq. (9), LFCs are calculated corresponding to $\theta=180^{\circ}$ and using energy methods corresponding local flexibility matrix $\mathbf{C}^{\mathbf{c}}(y, T)$ is obtained as

$$
\mathbf{C}^{\mathrm{c}}(y, T)=\left[\begin{array}{cccc}
C_{11}^{\mathrm{c}} & 0 & 0 & 0 \\
& C_{22}^{\mathrm{c}} & 0 & 0 \\
& & C_{33}^{\mathrm{c}} & C_{34}^{\mathrm{c}} \\
s y m & & & C_{44}^{\mathrm{c}}
\end{array}\right]
$$

where expressions of the elements of $\mathbf{C}^{\mathfrak{c}}(y, T)$ are taken from published works [15-16].

Using Eq. (10) and with the help of virtual work principle cracked stiffness matrix $\mathbf{K}^{\mathrm{c}}$ is computed as

$$
\mathbf{K}^{\mathrm{c}}=\boldsymbol{\Pi}^{\mathrm{T}}\left[\mathbf{C}^{\mathrm{c}}\right]^{-1} \boldsymbol{\Pi}
$$

where the transformation matrix $\Pi$ has been shown in published work of Gayen et al. [15-16].

The elementary EOMs for an FG shaft with stationary crack is written as

$$
\left(\mathbf{M}_{T}^{s}+\mathbf{M}_{R}^{s}\right) \mathbf{R}(t)-\boldsymbol{\Omega} \mathbf{G}^{s} \mathbf{p}(t)+\mathbf{K}^{s} \mathbf{p}^{s}(t)=\mathbf{f}^{s}(t)
$$

\footnotetext{
Corresponding author: d.gayen@,iitg.ernet.in
} 
where $\mathbf{M}_{T}^{s}$ and $\mathbf{M}_{R}^{s}$ are the elementary translational and rotational masses, $\mathbf{G}^{s}$ is the elementary gyroscopic matrix, $\mathbf{K}^{s}$ is the elementary un-cracked stiffness matrix, $\mathbf{p}^{s}(t)$ and $\mathbf{f}^{s}(t)$ are the elementary nodal displacement vector and external force vector of the shaft element. The details of elementary matrices of Eq. (12) were shown in published works $[8,15-16]$.

\subsection{Rigid Disk}

EOMs for rigid disk is expressed using Lagrangian equation as

$$
\left(\mathrm{M}_{T}^{d}+\mathrm{M}_{R}^{d}\right) \ddot{\mathrm{q}}^{d}-\Omega \mathrm{G}^{d} \dot{\mathrm{q}}^{d}=\mathrm{f}^{d}
$$

where individual matrices are taken same as in (Nelson and McVaugh [8]).

\subsection{Bearings Consideration}

Bearings are modeled based on classical linearized springs model as reported in Nelson and McVaugh [8] and is model the forces in each bearing are assumed to obey the following form of governing equations

$$
\mathrm{C}^{b} \dot{q}^{b}+\mathrm{K}^{b} q^{b}=\mathrm{f}^{b}
$$

where $\mathrm{f}^{b}$ is the bearing external force vector and bearing damping and stiffness matrices are

$$
\left[\mathrm{C}^{b}\right]=\left[\begin{array}{ll}
C_{v v}^{b} & C_{v w}^{b} \\
C_{v w}^{b} & C_{w w}^{b}
\end{array}\right],\left[\mathrm{K}^{b}\right]=\left[\begin{array}{ll}
K_{v v}^{b} & K_{v w}^{b} \\
K_{v w}^{b} & K_{w w}^{b}
\end{array}\right]
$$

\subsection{System Equations of Motion}

Based on work of Zorzi and Nelson [9], the resultant system EOMs are modified through the inclusions of internal viscous damping coefficient $\eta_{v}$ and internal hysteretic damping loss factor $\eta_{h}$ of the shaft material. Finally using extended Hamilton's principle, EOMs of the cracked shaft system including the rigid disk, bearing and internal damping effects could be expressed as

$$
\begin{aligned}
& \mathrm{M}^{e} \ddot{\mathrm{q}}{ }^{e}+\left(\eta_{v} \mathrm{~K}^{e}-\Omega \mathrm{G}^{e}+\mathrm{C}^{e}\right) \dot{\mathrm{q}}^{e} \\
& +\left[\frac{1+\eta_{h}}{\sqrt{1+\eta_{h}^{2}}} \mathrm{~K}^{e}+\left(\Omega \eta_{v}+\frac{\eta_{h}}{\sqrt{1+\eta_{h}^{2}}}\right) \mathrm{K}_{\text {cir }}^{e}\right] \mathrm{q}^{e}=\mathrm{f}_{\text {total }}^{e}
\end{aligned}
$$

The solution of the eigenvalue problem of Eq. (16) is determined in complex form as $\lambda_{n}=\xi_{n} \pm i \omega_{n}$, logarithmic decrement is defined as $\delta_{n}=-2 \pi \xi_{n} / \omega_{n}$ and stability threshold speed is obtained at which operation speed of rotor $\delta_{n}=0$, where $\xi, \omega$ and $n$ are damping constant, natural whirling frequency and mode number respectively.

\section{Results and discussions}

In the present study, an FG shaft having $D=0.1 \mathrm{~m}$ is considered and temperature dependent material properties in the constituents of $\mathrm{FG}\left(\mathrm{SS} / \mathrm{ZrO}_{2}\right)$ shaft are taken from Reddy and Chin [3] (also shown in Gayen et. al [15-16]). The FG shaft is modeled with 25 equal finite elements and supported by the simply supported boundary condition and with the identical un-damped isotropic bearing of stiffness coefficients $K_{v v}^{b}=K_{w w}^{b}=17.513 \mathrm{MN} / \mathrm{m}$ and $K_{v w}^{b}=K_{w v}^{b}=0$ at both ends. In the FE model, a disc is considered at center location with weight $1.406 \mathrm{~kg}$, polar and diametral moment of inertias $0.002 \mathrm{~kg} / \mathrm{m}^{2}$ and $0.0135 \mathrm{~kg} / \mathrm{m}^{2}$ respectively.

\subsection{Validation}

Due to lack of existing results on temperature dependent free vibration and stability analysis for a spinning FG shaft system. Therefore, a homogeneous shaft is selected for validating the present FE formulation and developed code in three steps.

\subsubsection{Influence of hysteretic internal damping on natural frequencies}

A steel shaft having $L=1.27 \mathrm{~m}, D=10.16 \mathrm{~cm}$, $\rho=7833 \mathrm{~kg} / \mathrm{m}^{3}$ and $E=206.80 \mathrm{GPa}$ are considered to validate the present $\mathrm{FE}$ formulation. Influence of hysteretic damping on natural frequencies in dimensionless form $\varpi_{n}\left(\varpi_{n}^{4}=\rho A L^{4} \omega^{2} / E I\right)$ is computed of a shaft with slenderness ratio $S R(=R / 2 L)$, and results are compared with the published work of $\mathrm{Ku}$ [10]. In Table 1, the results shows the change in $\varpi_{n r}$ is relatively smaller for higher $S R$ and also present results are well matched with published results.

Table 1 Influence of $\eta_{h}$ on $\varpi_{n}$ for an uniform non-spinning simply supported shaft

\begin{tabular}{cccccc}
\hline \multirow{2}{*}{ Modes } & $\mathrm{SR}$ & \multicolumn{2}{c}{$\eta_{h}=0.001$} & \multicolumn{2}{c}{$\eta_{h}=0.002$} \\
\cline { 2 - 6 } & $(R / 2 L)$ & Present & $\mathrm{Ku}[10]$ & Present & $\mathrm{Ku}[10]$ \\
\hline \multirow{3}{*}{$1 \mathrm{st}$} & 0.02 & 3.1308 & 3.1301 & 3.1316 & 3.1309 \\
\cline { 2 - 6 } & 0.06 & 3.0459 & 3.0407 & 3.0467 & 3.0414 \\
\cline { 2 - 6 } & 0.10 & 2.9112 & 2.8999 & 2.9119 & 2.9006 \\
\hline \multirow{3}{*}{ 2nd } & 0.02 & 6.2052 & 6.1923 & 6.2068 & 6.1943 \\
\cline { 2 - 6 } & 0.06 & 5.7112 & 5.6476 & 5.7126 & 5.6490 \\
\cline { 2 - 6 } & 0.10 & 5.1491 & 5.0493 & 5.1504 & 5.0560 \\
\hline
\end{tabular}

\subsubsection{Local flexibility coefficients (LFCs) of a fully open transverse cracked shaft}

In order to validate the LFCs, a shaft made of SS is considered with $D=0.1 \mathrm{~m}, L=1.25 \mathrm{~m}$. Dimensionless compliance $\bar{C}_{44}$ and $\bar{C}_{55}$ as a function of size of crack 
$\alpha / R$ has been determined and compared with published results of Chasalevris and Papadopoulos [19]. Results in Table 2 show an excellent agreement to verify the formulation of crack compliances.

Table 2 Dimensionless compliance $\bar{C}_{44}$ and $\bar{C}_{55}$ as a function of $\alpha / R$

\begin{tabular}{ccccc}
\hline \multirow{2}{*}{$\frac{\alpha}{R}$} & \multicolumn{2}{c}{$\bar{C}_{44}$} & \multicolumn{2}{c}{$\bar{C}_{55}$} \\
\cline { 2 - 5 } & Present & Ref. [19] & Present & Ref. [19] \\
\hline 0.04 & 0.0000349 & 0.000035 & 0.0029731 & 0.002973 \\
\hline 0.36 & 0.0747941 & 0.074794 & 0.5677802 & 0.567780 \\
\hline 0.68 & 0.8171641 & 0.817164 & 2.5852663 & 2.585270 \\
\hline 1.00 & 5.2663511 & 5.266350 & 7.7903871 & 7.790390 \\
\hline
\end{tabular}

\subsubsection{Natural frequencies of a simply supported shaft with a single crack}

The ratio between cracked and un-cracked natural frequencies are computed as a function of $\alpha / R$ and $L / D$, for a crack located at mid span of shaft and results are compared with published results of Sekhar and Prabhu [20] as shown in Table 3. It could be observed from Table 3 that the present results is well matched for $L / D=12.5$ and $L / D=8.0$.

Table 3 Variation of dimensionless natural frequencies with $\alpha / R$ for different $L / D$

\begin{tabular}{|c|c|c|c|c|c|}
\hline \multirow[b]{2}{*}{ Modes } & \multirow[b]{2}{*}{$L / D$} & \multicolumn{2}{|c|}{$\alpha / R=0.2$} & \multicolumn{2}{|c|}{$\alpha / R=1.0$} \\
\hline & & Present & $\begin{array}{l}\text { Sekhar and } \\
\text { Prabhu[20] }\end{array}$ & Present & $\begin{array}{l}\text { Sekhar and } \\
\text { Prabhu }[20\end{array}$ \\
\hline $1^{\text {st }}$ & & 0.9953 & 0.9958 & 0.7798 & 0.7882 \\
\hline $2^{\text {nd }}$ & 2 & 0.9999 & 0.9998 & 0.9839 & 0.9818 \\
\hline $1^{\mathrm{st}}$ & & 0.9931 & 0.9955 & 0.7050 & 0.7187 \\
\hline $2^{\text {nd }}$ & 0.0 & 0.9999 & 0.9997 & 0.9742 & 0.9771 \\
\hline
\end{tabular}

\subsection{Influence of $k, \Delta T, \alpha / R$ and elastic supports on natural frequency for an FG transverse cracked shaft}

In order to understand the influences of material gradient index $k$, temperature gradient $\Delta T$, size of crack $\alpha / R$, boundary conditions ( BCs) (clamped free C-F, simplysupported S-S, and clamped-clamped $\mathrm{C}-\mathrm{C}$ ), natural frequencies associated with vertical plane $\omega_{1 \mathrm{~V}}$ and horizontal plane $\omega_{1 \mathrm{H}}$ are computed for a non-rotating centrally located FG cracked shaft with $\theta=180^{\circ}$ having two discs located at $0.45 \mathrm{~m}$ and $0.9 \mathrm{~m}$ from left end. The discs are considered with the specification stated earlier and results are obtained for $R / 2 L=0.02$ and location of crack $L_{c} / L=0.5$ with temperature dependent material properties and listed in Table 4-5. The percentage reductions in natural frequencies are calculated as $\left.\varpi_{i}=\left(1-\omega_{i}^{\Delta T=0 \mathrm{~K}, 300 \mathrm{~K}, 600 \mathrm{~K}} / \omega_{i}^{\Delta T=0 \mathrm{~K}}\right) \times 100\right)$. It is observed from Table 4 that with increase in gradient index $k$ causes the $\%$ reduction in $\varpi_{1 \mathrm{v}}$ and $\varpi_{1 \mathrm{H}}$ due to transition of shaft from zirconia (lower $E$ and lower density) to stainless steel (higher $E$ and higher density) for a specific $\Delta T$, support condition and material distribution. Also with the increase in $\Delta T, \varpi_{1 \mathrm{~V}}$ and $\varpi_{1 \mathrm{H}}$ increase as material becomes softer at higher temperatures and also remarkable that the order of $\varpi_{1 \mathrm{~V}}$ and $\varpi_{1 \mathrm{H}}$ are C-C $>\mathrm{C}-\mathrm{F}>\mathrm{S}-\mathrm{S}$, respectively.

Table 4 Percentage reduction in $\omega$ with $\Delta T$ and $k$ of a nonrotating FG cracked shaft with BCs for $\alpha / R=0.8$

\begin{tabular}{cccccc}
\hline \multirow{2}{*}{ BCs } & \multirow{2}{*}{$\Delta T(\mathrm{~K})$} & \multicolumn{5}{c}{$\varpi_{1 \mathrm{~V}}$} \\
\cline { 2 - 6 } & & $k=0.5$ & $k=1.0$ & $k=5.0$ & $k=10.0$ \\
\hline \multirow{2}{*}{$\mathrm{C}-\mathrm{F}$} & 300 & 6.65 & 5.11 & 2.85 & 2.72 \\
\cline { 2 - 6 } & 600 & 11.76 & 9.94 & 7.46 & 7.82 \\
\hline \multirow{2}{*}{$\mathrm{S}-\mathrm{S}$} & 300 & 6.52 & 4.93 & 2.46 & 2.35 \\
\cline { 2 - 6 } & 600 & 11.52 & 9.61 & 6.85 & 7.23 \\
\hline \multirow{2}{*}{$\mathrm{C}-\mathrm{C}$} & 300 & 6.72 & 5.22 & 3.06 & 2.92 \\
\cline { 2 - 6 } & 600 & 11.90 & 10.12 & 7.78 & 8.15 \\
\hline \multirow{2}{*}{ BCs } & $\Delta T(\mathrm{~K})$ & \multicolumn{5}{c}{$\varpi_{1 \mathrm{H}}$} & \\
\cline { 2 - 6 } & & $k=0.5$ & $k=1.0$ & $k=5.0$ & $k=10.0$ \\
\hline \multirow{2}{*}{$\mathrm{C}-\mathrm{F}$} & 300 & 6.75 & 5.27 & 3.20 & 3.05 \\
\cline { 2 - 6 } & 600 & 11.96 & 10.21 & 7.95 & 8.35 \\
\hline \multirow{2}{*}{$\mathrm{S}-\mathrm{S}$} & 300 & 6.64 & 5.13 & 3.01 & 2.88 \\
\cline { 2 - 6 } & 600 & 11.80 & 10.01 & 7.70 & 8.07 \\
\hline \multirow{2}{*}{ C-C } & 300 & 6.71 & 5.22 & 3.12 & 2.98 \\
\cline { 2 - 6 } & 600 & 11.91 & 10.14 & 7.89 & 8.26 \\
\hline
\end{tabular}

Table 5 Percentage reduction in $\omega$ with $k, \Delta T$ and $\alpha / R$ of a non-rotating S-S FG cracked shaft

\begin{tabular}{cccccc}
\hline \multirow{2}{*}{$\alpha / R$} & $\Delta T(\mathrm{~K})$ & \multicolumn{5}{c}{$\varpi_{1 \mathrm{~V}}$} \\
\cline { 2 - 6 } & & $k=0.5$ & $k=1.0$ & $k=5.0$ & $k=10.0$ \\
\hline \multirow{2}{*}{0.0} & 300 & 6.78 & 5.32 & 3.26 & 3.11 \\
\cline { 2 - 6 } & 600 & 12.02 & 10.28 & 8.09 & 8.45 \\
\hline \multirow{2}{*}{0.4} & 300 & 2.49 & 1.77 & 1.15 & 1.11 \\
\cline { 2 - 6 } & 600 & 4.81 & 3.54 & 2.67 & 2.76 \\
\hline \multirow{2}{*}{0.8} & 300 & 6.52 & 4.93 & 2.46 & 2.35 \\
\cline { 2 - 6 } & 600 & 11.52 & 9.61 & 6.85 & 7.23 \\
\hline \multirow{2}{*}{$\alpha / R$} & $\Delta T(\mathrm{~K})$ & \multicolumn{5}{c}{$\varpi_{1 \mathrm{H}}$} & \\
\cline { 2 - 6 } & $k=0.5$ & $k=1.0$ & $k=5.0$ & $k=10.0$ \\
\hline \multirow{2}{*}{0.0} & 300 & 6.78 & 5.32 & 3.26 & 3.11 \\
\cline { 2 - 6 } & 600 & 12.02 & 10.28 & 8.09 & 8.45 \\
\hline \multirow{2}{*}{0.4} & 300 & 2.74 & 2.05 & 1.37 & 1.29 \\
\cline { 2 - 6 } & 600 & 5.25 & 4.03 & 3.06 & 3.07 \\
\hline \multirow{2}{*}{0.8} & 300 & 6.64 & 5.13 & 3.01 & 2.88 \\
\cline { 2 - 6 } & 600 & 11.80 & 10.01 & 7.70 & 8.07 \\
\hline
\end{tabular}


Table 5 shows that with the increase in $\alpha / R$, $\varpi_{1 \mathrm{~V}}$ and $\varpi_{1 \mathrm{H}}$ decrease for a specific $k$ and $\Delta T$. It also shows that reductions are relatively higher for higher values of $\Delta T$ due to the degradation of material properties with the rise in temperature gradient across radial direction in FG cracked shaft. Thus in a high temperature application designing FG shafts, power-law gradation $k$ may be chosen in such a way so that the reductions in $\varpi_{i}$ with temperature is minimized while keeping enough material at the outer layer for providing temperature resistance within desired limit.

\subsection{Influence of $L / D, k, \Delta T$ and disc on stability threshold speed of a FG shaft in a rotor-disc-bearing system}

Influences of $L / D, k, \Delta T$ and disc on stability threshold speeds $\Omega_{\text {th }}$ of an FG shaft system are examined with same dimension and temperaturedependent material properties stated earlier. FG shaft is supported on isotropic un-damped bearing with stiffness coefficients $K_{v v}^{b}=K_{w w}^{b}=17.513 \mathrm{MN} / \mathrm{m}, K_{v w}^{b}=K_{w v}^{b}=0$. The $\%$ reduction in $\Omega_{\text {th }}$ is defined as $\bar{\Omega}_{\mathrm{th}}=\left(1-\Omega_{\mathrm{th}}^{\Delta \mathrm{T}=0 \mathrm{~K}, 300 \mathrm{~K}, 600 \mathrm{~K}} / \Omega_{\mathrm{th}}^{\Delta \mathrm{T}=0 \mathrm{~K}}\right) \times 100$. Results are shown in Figs. 2-3. It is observed from Fig. 2 that $\bar{\Omega}_{\text {th }}$ increase with increase in $L / D$ and $\Delta T$ and also reduction in $\bar{\Omega}_{\text {th }}$ are appreceiable in case of shafts with low $L / D$ and at high $\Delta T$. Fig. 3 show that $\bar{\Omega}_{\text {th }}$ increases with decrease in $k$ due to mettalic content increase in the FG shaft and also with increase in $\Delta T$, these are minimum for the FG shaft with an optimal value of $k=5.0$ and again it increase. Therefore, designing in FG shafts gradient index can play great role to expose larger temperature gradients and higher spinning speeds and also FG shaft has an advantage over shaft made of SS.

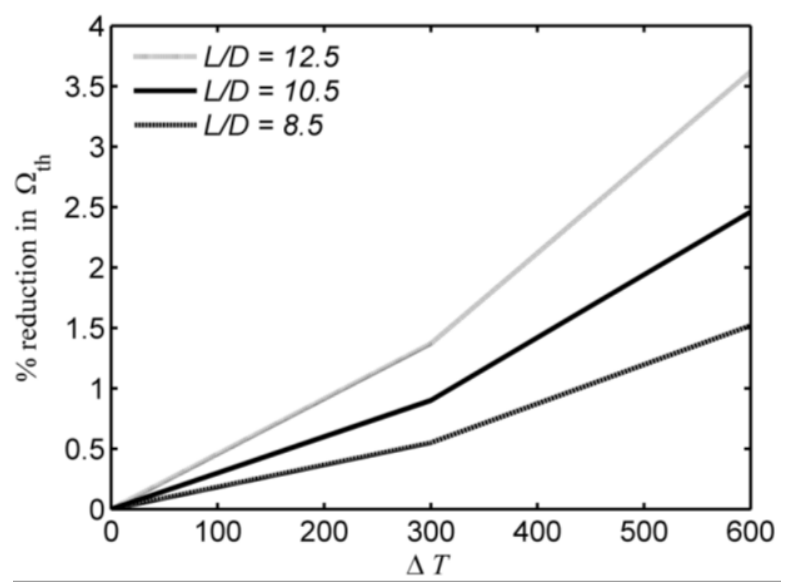

Fig. 2 Percentage reduction in $\Omega_{\text {th }}$ of a rotor-bearing system with $L / D$ and $\Delta \mathrm{T}$ for $k=5.0, \eta_{v}=0.0002 \mathrm{~s}$
The disc effect on $\Omega_{\text {th }}$ for the same FG rotor system with $k$ and $\Delta T$ for $L / D=12.5$ and,$\eta_{v}=0.0002 \mathrm{~s}$ and the location of single disc is $0.5 \mathrm{~m}$ from the left end and double discs are at $0.45 \mathrm{~m}$ and $0.9 \mathrm{~m}$ from the left end. The listed results in Table 6 indicate that with increase in number of disc mounting on FG shaft $\Omega_{\text {th }}$ reduced, as expected but also the $\Omega_{\text {th }}$ decrease with increase in $k$ as well as with increase in $\Delta T$ as the reason stated earlier.

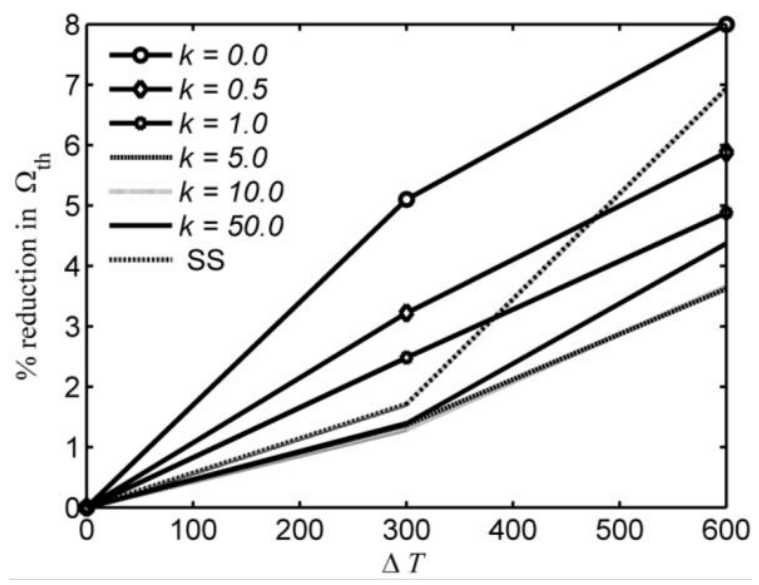

Fig. 3 Percentage reduction in $\Omega_{\text {th }}$ of a rotor-bearing system with $k$ and $\Delta \mathrm{T}$ for $L / D=12.5, \eta_{v}=0.0002 \mathrm{~s}$

Table 6 Stability threshold speed $\Omega_{\text {th }}$ (rpm) of a rotor-bearing system with $k$ and $\Delta T$ for $L / D=12.5$

\begin{tabular}{ccccccc}
\hline $\begin{array}{c}\Delta T \\
(\mathrm{~K})\end{array}$ & $\begin{array}{c}\text { No. of } \\
\text { disc }\end{array}$ & $k=0.0$ & $k=0.5$ & $k=1.0$ & $k=5.0$ & $k=10.0$ \\
\hline \multirow{3}{*}{0} & Nil & 5685 & 5440 & 5320 & 5100 & 5055 \\
\cline { 2 - 7 } & One & 5580 & 5350 & 5240 & 5035 & 4990 \\
\cline { 2 - 7 } & Two & 5515 & 5295 & 5185 & 4985 & 4945 \\
\hline \multirow{3}{*}{300} & Nil & 5395 & 5265 & 5190 & 5030 & 4990 \\
\cline { 2 - 7 } & One & 5295 & 5180 & 5110 & 4960 & 4925 \\
\cline { 2 - 7 } & Two & 5230 & 5125 & 5060 & 4915 & 4880 \\
\hline \multirow{3}{*}{600} & Nil & 5230 & 5120 & 5060 & 4915 & 4870 \\
\cline { 2 - 7 } & One & 5130 & 5035 & 4980 & 4850 & 4805 \\
\cline { 2 - 7 } & Two & 5070 & 4980 & 4930 & 4805 & 4760 \\
\hline
\end{tabular}




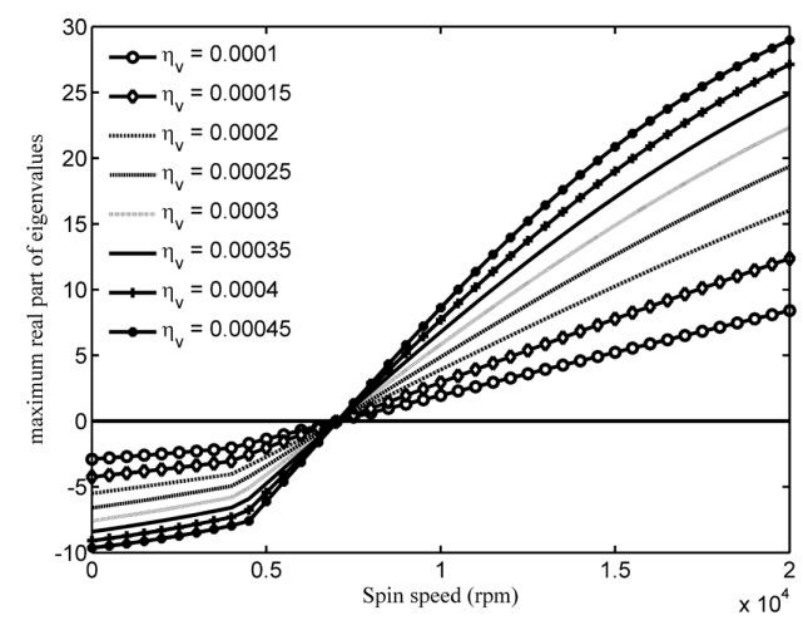

Fig. 4 Variation of maximum real part of a two disc rotorbearing having an FG shaft with $\eta_{v}$

Fig. 4 shows the variation of the maximum real part for the FG shaft system with different internal viscous damping $\eta_{v}$ for $k=5.0, \Delta \mathrm{T}=0 \mathrm{~K}$ and $L / D=12.5$ and it could be observed that with increase in $\eta_{v}$ the values of maximum real part decrease but stability threshold speeds are not changing because the shaft made FGM with the $k=5.0$ is fixed.

\subsection{Influence of $L / D, \alpha / R$ and $L_{c} / L$ on stability threshold speed of a FG cracked shaft in a rotor-disc-bearing system}

Influences of $L / D, \alpha / R$ and $L_{c} / L$ on $\Omega_{\text {th }}$ are examined for a two disc rotor-bearing system having an FG shaft with $\theta=180^{\circ}$. The FG cracked shaft is supported on two rigid end bearings with $L_{c} / L=0.14$ and $0.5, k=5.0, \Delta T=0 \mathrm{~K}, \eta_{h}=0.0002$ and $\eta_{v}=0.0002 \mathrm{~s}$. In the present study, the normalized threshold speeds $\bar{\Omega}_{\text {th }}$ with $\alpha / R$ and $L / D$ are computed and results are tabulated in Table 7. Here, normalization is done with respect of an un-cracked shaft. It is observed that variation in $\bar{\Omega}_{\text {th }}$ due to crack are appreciable with low $L / D$ shaft and also effect of reduction is more for mid span crack compared to other location of crack, because of crack is closer to antinodal points.

Table 7 Variation of $\bar{\Omega}_{\mathrm{th}}$ for an FG shaft with $L / D$ and $\alpha / R$ for $L_{c} / L=0.14$ and $0.5, k=5.0, \Delta T=0 \mathrm{~K}$

\begin{tabular}{|c|c|c|c|c|c|}
\hline$L / D$ & $L_{c} / L$ & $\alpha / R=0.2$ & $\alpha / R=0.4$ & $\alpha / R=0.6$ & $\alpha / R=0.8$ \\
\hline 12.5 & \multirow{3}{*}{0.14} & 0.9987 & 0.9933 & 0.9786 & 0.9498 \\
\hline 10.5 & & 0.999 & 0.9924 & 0.9781 & 0.9615 \\
\hline 8.5 & & 0.9994 & 0.9921 & 0.983 & 0.982 \\
\hline 12.5 & \multirow{3}{*}{0.50} & 0.9933 & 0.9672 & 0.907 & 0.7885 \\
\hline 10.5 & & 0.9924 & 0.9615 & 0.8982 & 0.8041 \\
\hline 8.5 & & 0.9915 & 0.9575 & 0.9108 & 0.903 \\
\hline
\end{tabular}

\section{Conclusions}

The present work arrives at the following conclusions:

- Temperature dependent material properties have significant impacts on calculating dynamic responses of a radially FG shaft with different gradation law such as P-FGM, E-FGM and SFGM.

- Material gradient index and temperature gradient yields a significant role on natural frequencies and stability threshold speeds of the FG cracked shaft system. Therefore, with the conjunction of temperature gradient and gradient index plays an important role in designing such FG shafts in using large temperature gradients and operating at high spinning speeds in a rotating system.

- It could be observed from various responses of shaft made of SS and FGM that FG shaft can operate at higher spin speed than that of SS shaft in using as rotating machinery element.

- Finally, present work can be recommended in modeling and analysis of FG shaft having multiple cracks with temperature dependent materials properties followed by different gradation laws.

\section{References}

1. M. Koizumi, Ceram. Trans. 34, 3-10 (1993)

2. Y. Miyamoto, W.A. Kaysser, B.H. Rabin, A. Kawasaki, R.G. Ford, Functionally Graded Materials: Design, Processing and Application (Kluwer Academic Publishers, London, 1999)

3. J.N. Reddy, C.D. Chin, J. Therm. Stresses 21, $593-$ 626 (1998)

4. A. Mahi, E.A. Adda Bedia, A. Tounsi, I. Mechab, Compos. Struct. 92(8), 1877-1887 (2010)

5. A. Shahba, R. Attarnejad, M. T. Marvi, S. Hajilar, Compos. Part B Eng. 42(4), 801-808 (2011)

6. D. Gayen, T. Roy, Proc. Inst. Mech. Eng. Part C: J. Mech. Eng. Sci. 228(18), 3306-3321 (2014)

7. C.A. Papadopoulos, Mech. Syst. Signal Pr. 22(4), 763-789 (2008)

8. H.D. Nelson, J.M. Mcvaugh, ASME J. Eng. Ind. 98, 593-600 (1976)

9. E.S. Zorzi, H.D. Nelson, ASME J. Eng. Power 99(1), 71-76 (1977)

10. D.M. Ku, Mech. Syst. Signal Pr. 12(5), (1998) 599610

11. C.A. Papadopoulos, A.D. Dimarogonas, ASME J. Vib. Acoust. Stress 110(3) 356-359 (1988)

12. S.C. Huang, Y.M. Huang, S.M. Shieh, J. Sound Vib. 162(3), 387-401 (1993)

13. L. Chen, H. Chen, J. Sound Vib. 188(4), 497-513 (1995)

14. A.S Sekhar, J.K Dey, Mech. Mach. Theory 35(12), 1657-1674 (2000) 
15. D. Gayen, D. Chakraborty, R. Tiwari, Eur. J. Mech.A/Solids 61, 47-58 (2017)

16. D. Gayen, D. Chakraborty, R. Tiwari, Proceedings of the ASME Gas Turbine India Conference, December 7-8, 2017, Bangalore, India.

17. Y.S Touloukian, Thermophysical Properties of High Temperature Solid Materials (McMillan, New York, 1967)

18. H. Tada, P.C. Paris, G.R. Irwin, The Stress Analysis of Cracks Handbook (Del Research Corporation, Hellertown, Pennsylvania, USA, 1973)

19. A.C. Chasalevris, C.A. Papadopoulos, Mech. Syst. Signal Pr. 20(7), 1631-1673 (2006)

20. A.S. Sekhar, B.S. Prabhu, J. Sound. Vib. 157(2), 375-381 (1992) 